Carlos de la Isla, De esclavitudes y libertades. Ensayos de ética, educación y política, 2006, México, Miguel Ángel Porrúa/ITAM, 297 pp.

E

este libro, Carlos de la Isla presenta una recopilación de textos publicados con anterioridad y cuyo enfoque ha sido una de las mayores preocupaciones del autor: la ética. Ante la situación particular del mundo, en que la corrupción, la avaricia, el poder por el poder y la inhumanidad han permeado todos sus rincones, desde hace ya varios años De la Isla ha intentado llamar la atención de sus alumnos, colegas y público en general sobre que, para remediar este estado de cosas, debemos echar mano de la ética. "La única verdadera solución se encuentra en un cambio de actitud ética a todos los actores que causan tantos desastres" (p. 7). La selección en De esclavitudes y libertades está dividida en cuatro apartados que conectan a la ética con lo propio del ser humano: la educación, los quehaceres sociales, la libertad y reflexiones generales.

En el primer bloque, De la Isla se ocupa de la concordancia entre la ética y la educación, pues es ahí — dice_ - donde se forman los seres humanos. En el ensayo "Es necesaria una nueva actitud ética en el mundo", hace un llamado a las universidades para que se vinculen con las acciones humanas, con el objeto de que el conocimiento científico "deje de ser dominado por el impulsopoder y que el impulso-amor vuelva a ser el móvil del conocimiento" (p. 16). Cuánta razón tiene el autor cuando afirma que el sistema educativo está lleno de perversiones al enseñar el saber por el saber y al olvidar lo particularmente humano del conocimiento: la responsabilidad social y la justicia. En los ensayos sobre este tema nos encontramos con muchas referencias a pensadores que, desde siempre, han puntualizado la importancia de la ética y del conocimiento humano en la formación de los estudiantes: Platón, José Ortega y Gasset, Cornelius Castoriadis, Henri Bergson, Bertrand Russell, Giovanni Papini, 
José Vasconcelos y muchos otros, a los que remite De la Isla en apoyo de sus posiciones.

Encontramos también constantes referencias a los studia generalia, los estudios generales que, en la visión de De la Isla, son la esencia de la universidad. En los ensayos "Hacia una educación del hombre humano", "Un acercamiento a la educación del hombre humano", "Reflexiones sobre el método dialógico" y "Nota sobre los estudios generales" se insiste en la idea de incluir en la educación materias de esta índole para dotar de pensamiento crítico al estudiante y acercarlo al humanismo. "En esa reflexión crítica amplísima se hallan innumerables elementos y razones para gestar las propias ideas y convicciones que construyan la defensa contra los valores dominantes que pretenden abarcarlo todo, someterlo todo" (p. 60). En este punto el autor recuerda el ensayo de Edgar Morin "El imposible realismo. La antropolítica", en el que conmina a una nueva ética del mundo frente a la incertidumbre de la realidad que se vive actualmente. Para Morin, igual que para Carlos de la Isla, "la política debe tratar la multidimensionalidad de los problemas humanos". ${ }^{1}$ Se debe echar mano de la ética para construir lo que Morin denomina la "antropolítica": una política del hombre.

El segundo apartado del libro está dedicado a la relación de la ética con la política en el sentido más amplio del término. En el primer ensayo, "Algunas doctrinas éticas", De la Isla revisa diversas propuestas éticas ligadas a la política: el individualismo, el utilitarismo, el deontologismo, el igualitarismo y el marxismo. Concluye que le parece "dramático" "que las doctrinas más negativas y plagadas de objeciones sean las que tienen mayor vigencia en el mundo" (p. 135).

En los siguientes textos, De la Isla explica y coloca la ética en su justo valor dentro de diversas acciones humanas que están relacionadas con la política: la empresa, la publicidad, el bien común y la propiedad. El autor recuerda que la situación actual está muy alejada de la ética de la política y convalida la construcción de utopías, como lo diría Morin, para provocar un cambio a favor de la justicia y el bien; propone que si las innumerables revoluciones de la historia no han podido cambiar verdaderamente la situación, entonces lo que se necesita es una revolución de la ética que abarque todo lo humano (p. 185).

${ }^{1}$ Edgar Morin y Ann Brigitte Kern, "El imposible realismo. La antropolítica”, en Edgar Morin y Anne Brigitte Kern, Tierra Patria, 1993, Barcelona, Kairós, pp. 151-174. 
La tercera sección reúne los ensayos que Carlos de la Isla ha escrito sobre la libertad. En estos textos se percibe una continuidad con los anteriores, pues en conjunto defienden la idea de que para alcanzar una verdadera ética de la política se debe actuar con y hacia la libertad, una libertad que deje de lado el poder y que suprima las persistentes relaciones de esclavitud; una libertad ligada al amor humano y a la autenticidad. Por ello, "ante la quiebra del sistema fundado sobre valores contables, hedonistas e individualistas que mueven al mundo, es necesario presentar los atractivos de ideales personales, de estilos de vida superiores: el placer de saber, el gozo estético, el ocio de la contemplación, el gusto del bien por hacer el bien" (p. 265). Ahí está la libertad, deja claro el autor; ahí está el amor, el bien y la justicia, todos enmarcados en un comportamiento ético que abarque lo que es propiamente humano y no lo que algunos etiquetan de humano, pero que son solo engaños.

El último apartado comprende textos que son en realidad discursos pronunciados por Carlos de la Isla en diversas conmemoraciones y homenajes. Los dos primeros están dedicados a Ramón Xirau y a Joaquín Xirau, respectivamente. Al principio, pareciera que rompen con el hilo conductor del libro que refiere a la ética, pero no es así. Estos discursos han sido colocados en este lugar para que el lector entienda, en la obra de estos personajes, lo que el autor ha venido diciendo. En pocas palabras, los pone de ejemplo de lo que verdaderamente es vivir y llevar a cabo la ética. El último ensayo, "Pensamiento y palabra", es breve pero inspirador, y deja encargada la tarea de reflexionar, de pensar, pero sobre todo de expresar nuestros pensamientos guiados por la búsqueda de la verdad. "Es afortunado aquel que siempre encuentra la expresión adecuada de sus pensamientos, y más afortunado el que ajusta su vida a la verdad de lo que piensa" (p. 297).

En De esclavitudes y libertades Carlos de la Isla muestra, con su recopilación de reflexiones en búsqueda de la verdad, que él es ejemplo de conducta ética, una ética no solo plasmada en el papel, sino llevada a la vida diaria, a la trasmisión del saber con el afán de construir un mundo más justo, más próspero, pero sobre todo, más humano.

\section{VALERIA ZEPEDA}

Departamento Académico de Estudios Generales, ITAM 